\title{
La adopción internacional en España
}

\author{
José Ocón Domingo
}

Universidad de Granada. Facultad de Ciencias Políticas y Sociología

C/Rector López Argüeta, s/n. 18170 Granada

joseocon@ugr.es

\section{Resumen}

En este artículo se recogen las circunstancias que posibilitaron la implantación de la adopción internacional a partir de la Segunda Guerra Mundial, así como se analizan las funciones atribuidas a las entidades responsables de protección del menor y a las entidades colaboradoras de adopción internacional durante todo el proceso adoptivo. Asimismo, se contempla la normativa española, de conformidad con los presupuestos establecidos en la normativa internacional, y se proporcionan datos estadísticos que informan sobre la evolución experimentada por este recurso de protección y por la adopción nacional en los últimos años en España. Finalmente, se vierten algunas reflexiones sobre los peligros asociados a la práctica de la adopción de niños extranjeros.

Palabras clave: niños, adopción nacional, normativa, protección, datos estadísticos.

\section{Abstract. The International Adoption in Spain}

The circumstances which allowed the introduction of international adoption after World War II are reviewed in this article, together with the functions allocated to bodies responsible for protecting minors and to co-operating entities with international adoption throughout the whole process of adoption. Likewise Spanish norms are considered, according to the premises laid down in international regulations. Statistical data are given concerning the development of this resort to protection and national adoption during recent years in Spain. Finally, some thoughts about the dangers of adopting foreign children are expressed.

Key words: children, national adoption, norms, protection, statistical data.

\section{Sumario}

Introducción Actualidad de la adopción internacional

Antecendentes y fundamentos de la adopción internacional en España

Conclusiones

El proceso de adopción internacional

Bibliografía

El papel de las agencias de adopción internacional 


\section{Introducción}

La adopción, según los estudios realizados en España, ${ }^{1}$ constituye un recurso eficaz para los niños huérfanos, abandonados o con ciertas dificultades sociales. Esta medida (en sus vertientes nacional e internacional) está demostrando su capacidad para ayudar al desarrollo de la personalidad de los niños, frente a las consecuencias perversas que pueden derivarse de la vida en las instituciones. Autores clásicos, como R. Spitz (1945), se referirá a ellas con el término "síndrome de hospitalismo"; J. Bowlby (1951) habla de "privación maternal»; y Goffman (1961) de "Instituciones Totales» (Ocón 2000).

Aunque actualmente, en España, los centros de acogida se alejan sobremanera de las instituciones clásicas, esta circunstancia no impide que, antes de la institucionalización, las entidades públicas responsables de los menores opten por medidas de permanencia del menor en su propio entorno. Cuando esto no sea posible prefieren el acogimiento familiar y la adopción. ${ }^{2}$ Sin embargo, por cuestiones relacionadas con el tamaño de las instituciones, el excesivo número de internados, la mezcla de edades, la atención inadecuada y/o poco especializada, etc., estas distancias con los modelos tradicionales se nos antojan menores en los países poco desarrollados. De modo que la adopción internacional constituye una opción muy adecuada para optimizar la vida y el futuro de millones de niños.

\section{Antecedentes y fundamentos de la adopción internacional}

Los sentimientos despertados en torno a los niños huérfanos de la Segunda Guerra Mundial fundamentaron el auge de la adopción internacional (Giberti 1992). Así, entre los años 1948 y 1962, las familias norteamericanas adoptarán unos 2.000 niños alemanes y 3.000 japoneses. No obstante, la adopción internacional perderá importancia, sobre todo en Europa, a partir de los años noventa. Países como Suecia, Holanda y Dinamarca sólo adoptaron en las últimas décadas de dos a cuatro niños por cada millón de habitantes, frente a los cincuenta por millón de los años sesenta. En opinión de Hoksbergen (1997), este descenso aparece muy unido a un mayor y mejor

1. Pueden consultarse, básicamente, las obras de P. AMORÓs (1987): La adopción y el acogimiento familiar. Una perspectiva socioeducativa, Madrid: Narcea.; Martí X. MARCH (1993): La adopción en Mallorca. Una investigación evaluativa, Palma de Mallorca: Consejería de Gobernación; J. Palacios y otros (1997): La adopción en Andalucía, Sevilla: Junta de Andalucía, Consejería de Asuntos Sociales; y J. OCÓN: Aspectos psicosociales de la adopción en Andalucía (una perspectiva socio-histórica y jurídico-administrativa), Departamento de Sociología, Universidad de Granada (tesis doctoral aún no publicada).

2. España se ha sumado a estas políticas desinstitucionalizadoras más modernas, como se desprende de los datos publicados por el Defensor del Pueblo Español (1991), que ofrece la cifra de 24.406 menores en acogimiento residencial y 2.913 en acogimiento familiar en España en 1989. Siete años después, en 1996, pueden observarse estos cambios: 13.370 en acogimiento residencial y 11.529 en acogimiento familiar, según datos del Defensor del Pueblo Andaluz (1999). 
conocimiento de los problemas psicológicos asociados a esta modalidad de adopción.

A partir de los años noventa, en Estados Unidos, Europa y Australia, la adopción entre países ascendió en importancia. En Italia, por ejemplo, se adoptaron 1.847 niños durante el año 1992, elevándose hasta 2.448 en 1994 (un incremento del $32,5 \%)$. Los países que aportaron más niños fueron Brasil (677), Rumania (396), Colombia (250) y Rusia (174) (Dell'Antonio 1996). En Francia se llegó a la nada despreciable cifra de 3.528 niños en el año 1997, sobre todo originarios de Vietnam (1.328), Colombia (234), Madagascar (174), Rusia (173) y Brasil (167) (Fédération Enfance et Familles d'Adoption 1998).

El establecimiento de políticas más restrictivas en torno a la adopción por Vietnam (año 1975) y Corea (en 1980) y el descenso de nacimientos no deseados experimentado por Singapur, Hong Kong y Corea, trasladarán este protagonismo a los países de América Latina (Giberti 1992). El crecimiento de la demanda de niños se produce en España con veinte años de retraso con relación a otras naciones europeas: unos años antes de asentarse el modelo de protección de la infancia inherente a la Ley 21/1987, de 11 de noviembre (Mato 1997). Esta circunstancia ha hecho que España ofrezca actualmente cotas muy similares a las obtenidas, entre las décadas de los setenta y ochenta, por Suecia, Noruega y Países Bajos (García Sanz 1997).

Los años setenta, pues, marcan la verdadera demanda de niños en condiciones de ser adoptados en los países más desarrollados de Europa. Este auge surge como consecuencia de la disminución de menores susceptibles de ser adoptados internamente, básicamente por el descenso de la natalidad, las prácticas contraceptivas, las políticas de apoyo a la familia y, en general, el incremento de recursos sociales con esta finalidad (Montané y García 1991; Calvo 1994; Montané 1996). Pero la reducción de niños adoptables en España es una consecuencia directa de políticas propias de un país desarrollado, y no de trabas de naturaleza legal o burocrática (Merín Cañada 1994).

Junto a situaciones tan dolorosas como la extracción de órganos, la prostitución, la explotación laboral, el reclutamiento militar, etc., la imperfección legislativa puede ocasionar que los niños de los países más pobres caigan víctimas del tráfico internacional, cuando se procede a una adopción. Un magnífico ejemplo, tanto de adopción internacional como nacional, se materializa en el desmesurado número de niños adoptados incorrectamente en Rumania (tras la caída del régimen de Ceaucescu), en virtud de la Ley número 11, de 1 de agosto de 1990. Esta legislación toleró la adopción privada de entre 18.000 y 22.000 niños rumanos. ${ }^{3}$ Bajo precio pactado fueron hechos bastante frecuentes los consentimientos maternos en el hospital, los registros civiles con los nombres de los posteriores adoptantes y la implicación de intermediarios en representación de las partes implicadas (Zugravescu y Iacovescu 1991).

3. Según el trabajo de un grupo de expertos bajo los auspicios de dos ONGs: Defensa de los Niños Internacional (DEI) y Servicio Social Internacional (SSI) (Zugravescu y Iacovescu, 1991). 
En determinados países sudamericanos, el engaño a las madres en las maternidades para hacerles creer que sus hijos habían nacido muertos, la compra de bebés y el robo de niños con destino a la adopción ha podido demostrarse. En Perú, con motivo de la creación de una Asociación de Padres de Niños Desaparecidos, que denunció estos hechos, «[...] se logró la desarticulación de al menos ocho redes, que tenían en nómina a 34 jueces y a importantes personalidades del Gobierno» (Cernuda y Sáenz-Díez 1999: 191). También Audusseau-Pouchard (1997), refiriéndose a un artículo publicado en la revista Cambio 16, en 1993, indica que desaparecen al año en México unos veinte mil niños, cuatro mil en Brasil, dos mil en Colombia, ochocientos en Perú, quinientos en Argentina y trescientos en Guatemala.

Distintos organismos de la comunidad internacional vienen preocupándose por articular un conjunto de normas, medidas y garantías que eviten estos atentados contra los niños. En lo que respecta a la adopción internacional, ${ }^{4} \mathrm{el}$ garante fundamental es la Convención de las Naciones Unidas sobre los Derechos del Niño de 1989. ${ }^{5}$ Así se indica en su artículo 21: «Los Estados Partes que reconocen o permiten el sistema de adopción, cuidarán de que el interés superior del niño sea la consideración primordial y velarán porque la adopción del niño sólo sea autorizada por las autoridades competentes [...]» (apartado $a$ ), «Reconocerán que la adopción por personas que residan en otro país puede ser considerada como otro medio de cuidar del niño, en el caso de que éste no pueda ser colocado en un hogar de guarda o entregado a una familia adoptiva o no pueda ser atendido de manera adecuada en el país de origen» (apartado b), «Velarán porque el niño que haya de ser adoptado en otro país goce de salvaguardas y normas equivalentes a las existentes respecto a la adopción en el país de origen" (apartado c). "Adoptarán todas las medidas apropiadas para garantizar que, en el caso de adopción en otro país, la adopción no dé lugar a beneficios financieros indebidos para quienes participan en ella» (apartado $d$ ), «y se esforzarán, dentro de este marco, por garantizar que la colocación del niño en otro país se efectúe por medio de las autoridades y organismos competentes» (apartado e). Junto a esta Convención, como veremos, el Convenio de La Haya de 1993, relativo a la protección del niño y a la cooperación en materia de adopción internacional, ${ }^{6}$ ratificado por España en $1995,{ }^{7}$ se erige en el mejor instrumento.

4. El primer documento relacionado con este consenso internacional es la Declaración de la ONU, de 3 de diciembre de 1986, sobre los «Principios sociales y jurídicos aplicables a la protección y bienestar de los niños, con especial referencia a las prácticas en materia de acogimiento y adopción tanto nacional como internacional».

5. Ratificado por España el 30 de noviembre de 1990 (BOE núm. 313, de 31 de diciembre).

6. Para que el Convenio sea realmente efectivo es necesario que un elevado número de países de origen y de recepción forme parte del mismo, pues, en caso contrario, los futuros padres adoptivos o los intermediarios se dirigirán por sí mismos a los Estados ajenos al Convenio para hacerse con los niños con más facilidad. Esta forma de proceder iría en contra del interés del menor y perpetuaría las adopciones irregulares y fraudulentas (Borrás 1996).

7. BOE de 1 de agosto. 


\section{El proceso de adopción internacional}

El ajuste de la adopción a la normativa internacional y a la de los Estados implicados ha de ser muy riguroso, si se quieren asegurar los derechos de los niños. Será el menor quien tendrá que abandonar su nación para adaptarse e integrarse en una familia y en un país de características jurídicas y socioculturales muy diferentes. Este traslado puede verse acompañado de situaciones de inseguridad para el adoptado, que están previstas en el Convenio de la Haya (1993), donde se matiza: «[...] el niño gozará, en el Estado de recepción y en todo otro Estado contratante en que se reconozca la adopción, de derechos equivalentes a los que resultan de una adopción que produzca tal efecto en cada uno de los Estados» (art. 26.2). Por ello los técnicos de los equipos especializados al servicio de los organismos responsables de cada una de las Comunidades Autónomas deben abordar minuciosamente, durante el estudio preadoptivo, ${ }^{8}$ los siguientes aspectos (Galli y Volpe 1991):

1. Área social: Condiciones de habitación y espacio; situación económica y laboral; estructuras sociales y sanitarias de la zona de residencia; tipología de relaciones con familia, amigos, vecinos, etc.; actividades extralaborales; estilo de vida y tiempo libre.

2. Área psicológica: Motivaciones manifiestas y latentes; historia evolutiva del individuo o de los cónyuges; estado de salud; estructura de la personalidad; infertilidad y esterilidad; la adopción en personas fértiles con o sin hijos; adopción por solteros; fantasías y deseos sobre el futuro hijo; fantasías sobre los orígenes del niño y la comunicación de la condición de adoptado; disponibilidad para adoptar niños con características especiales: minusválidos, grupo de hermanos, etc.

Junto a la oportuna selección de los aspirantes, para ayudar al niño a asumir las circunstancias de la adopción, es imprescindible contar con unos servicios post-adoptivos adecuados. Así se establece en el artículo 9, apartado $c$, del Convenio de la Haya: «[...] las Autoridades Centrales promoverán el desarrollo de servicios en materia de adopción y para el seguimiento de adopciones». Además de estas cuestiones, los profesionales implicados procurarán que los padres adoptantes reciban la máxima información sobre la historia del niño y sobre su estado médico, psicológico y social. Estos detalles, en su conjunto, serán imprescindibles en tareas de "revelación» al adoptado de sus circunstancias, así como para su buen cuidado y educación. El niño, antes de producirse la entrega, tiene derecho a tener información detallada sobre su nueva familia

8. En la actualidad, para agilizar el procedimiento, se han firmado acuerdos entre los organismos responsables de algunas Comunidades Autónomas y los Colegios Profesionales de Psicólogos y Trabajadores Sociales para que, por turno de oficio, puedan proceder a emitir los preceptivos informes psicosociales necesarios para la práctica de las adopciones nacionales e internacionales. 
y futuro lugar de residencia, así como a recibir ayuda psicológica para superar la inevitable separación de su entorno sociocultural.

Una vez obtenida la declaración de idoneidad del adoptante o adoptantes la adopción seguirá las estipulaciones, bastantes semejantes, de cada una de las CC. AA. A modo de orientación, la CC.AA. de Valencia se acomoda al siguiente proceso (Dirección General de la Familia y Adopciones 1999):

1. Envío del expediente por parte del organismo competente español al organismo correspondiente del país de origen del adoptando.

2. Estudio del expediente por el organismo competente en materia de adopciones del país de origen y valoración de las características de la familia para adecuarlas al niño.

3. Comunicación de la preasignación del niño al organismo que, territorialmente, sea el responsable de las adopciones de menores, así como a la entidad colaboradora de adopción internacional, si la hubiere.

4. Información a la familia para que formule su aceptación del menor.

5. Comunicación al organismo del país de origen para que proceda a la elevación de una propuesta de adopción ante el juzgado correspondiente. Ésta se produce tras la conformidad de la entidad pública española responsable con las características del niño.

6. Inscripción del niño en el Registro Civil consular y en el libro de familia, tras la emisión de la resolución judicial y siempre que se trate de una adopción plena. También la familia puede solicitar un visado de entrada en España para realizar la inscripción del niño, después de su llegada, en el Registro Civil central y en el libro de familia.

7. Formalización, en el supuesto de que lo exija la legislación del país de origen, de un compromiso de seguimiento que garantice el mayor bienestar del niño. Será suscrito por la entidad pública responsable, la familia adoptiva y, si están autorizadas para ello, por las entidades mediadoras de adopción internacional.

\section{El papel de las agencias de adopción internacional}

La intervención de las agencias o entidades colaboradoras de adopción internacional (en adelante ECAIs), que nace en nuestro país bajo un marco legislativo, nacional e internacional bastante bien definido, resulta fundamental. En efecto, con anterioridad a la regulación establecida por el Convenio de la Haya (1993), los aspirantes a un niño fuera de sus fronteras tenían que enfrentarse solitariamente a una serie de avatares relacionados con la búsqueda de un niño (quizás distinto al deseado y con total desconocimiento de su historia); contactos con distintas personas (normalmente interesadas en explotar económicamente a la familia biológica y a la demandante); ansiedades; extorsiones; trabas burocráticas en España y en el país de origen, etc.

Actualmente, en virtud del artículo 9 de este Convenio, se establece que las autoridades centrales de los distintos gobiernos autonómicos «[...] toma- 
rán, ya sea directamente o con la cooperación de autoridades públicas o de otros organismos debidamente acreditados, todas las medidas apropiadas para [...] facilitar, seguir y activar el procedimiento de adopción». También, en su artículo 11, se dice que estos organismos deben perseguir únicamente fines no lucrativos y estar dirigidos por personas cualificadas. La entrada en vigor en España de estos convenios conduce a la aprobación en nuestro país de la actual Ley Orgánica 1/1996, de 15 de enero, de protección jurídica del menor, de modificación parcial del Código Civil y de la Ley de enjuiciamiento civil. ${ }^{9}$ Entre otros muchos aspectos relacionados con la protección, con esta ley se pretende garantizar los derechos de los niños y la legalidad de los procesos de adopción internacional. Su artículo 25 da cabida a las ECAIs y les encomienda funciones de mediación, de asesoramiento e intervención. También ha propiciado que las distintas Comunidades Autónomas puedan contar con ECAIs y regular su acreditación y funciones en los procesos adoptivos internacionales.

El Decreto de la Consejería de Asuntos Sociales 454/1996, de 1 de octubre, de la Junta de Andalucía, cuyo contenido es similar al de otras Comunidades Autónomas, puede servir de referente. Para la acreditación de una ECAI ${ }^{10}$ se necesitan estos requisitos: ser asociaciones o fundaciones sin ánimo de lucro y recoger en sus estatutos la finalidad de proteger a los menores; contar con un equipo multiprofesional formado por un psicólogo, un licenciado en derecho y un trabajador social; disponer de los medios materiales necesarios; estar dirigidas por personas cualificadas y presentar un proyecto económico para justificar los gastos de actuación; y tener su domicilio social o delegación en Andalucía, así como representación en el Estado para el que solicitan su acreditación.

Entre las obligaciones, figuran la de cumplir con lo estipulado en la legislación española y con la del Estado para el que hayan sido acreditadas; asegurar la ausencia de pago por la adopción (a excepción de lo establecido legalmente para la tramitación de documentación); ${ }^{11}$ informar a la Dirección General de Infancia y Familia ${ }^{12}$ (autoridad central en Andalucía) sobre los solicitantes que causen baja, en torno a los expedientes que envíen a cada Estado y respecto a los menores que hayan llegado a España; elaborar una memoria sobre las actividades realizadas y un balance económico; mantener reuniones periódicas con los equipos técnicos de adopciones y remitir a las autoridades cualquier tipo de anomalía durante el proceso.

9. BOE núm. 15 , de 17 de enero.

10. Algunas de las ECAIs que están funcionando en España responden a las siguientes siglas: ADDIA, AAIM, AASF, ADOPTA, AIPAMR, ASEFA, ANDAI, ASRHAM, AYA, ACI, TRAJANO, PIAO, etc.

11. La cantidad total que puede costar la formalización de una adopción internacional es variable, según los países de origen de los niños. Así, si la tramitación cuesta en Perú en torno a las 600.000 pesetas o en la República Dominicana unas 800.000, esta cifra puede llegar a alcanzar en Paraguay 2.000.000 de pesetas y en Turquía 2.500.000 pesetas (Corva y Ortega 1997).

12. Antes Dirección General de Atención al Niño. 
La intervención de las ECAIs, en definitiva, reporta al proceso de adopción internacional las ventajas siguientes (Hendricks 1995): el trabajo se realiza sin ánimo de lucro; se posibilita a las autoridades administrativas el control del proceso; las autoridades del país de origen siguen informadas sobre la evolución del niño; los que intervienen actúan de buena fe; se proporciona una imagen positiva de la adopción y el número de niños bajo esta medida resulta incrementado.

\section{Actualidad de la adopción internacional en España}

Los cambios experimentados en España en los terrenos económico, cultural, sexual, familiar, etc., han mejorado la situación de la infancia y los procesos de adopción nacional e internacional. Mientras la adopción se ha concebido tradicionalmente como un recurso encaminado a satisfacer los deseos y necesidades de los adultos en detrimento de los niños, en la actualidad persigue todo lo contrario. Las diversas actuaciones relacionadas con la adopción internacional han de respetar, en concordancia con la normativa internacional suscrita por España, un conjunto básico de postulados. Siguiendo a Calvo ${ }^{13}$ (1994: 86-90), se recogen la primacía del interés del menor sobre cualquier otro, la permanencia en el propio entorno familiar y sociocultural del menor, la constitución de la adopción internacional por autoridades competentes y el derecho del niño a beneficiarse de una protección y de un marco normativo equivalente al del país de acogida.

Por otra parte, la organización del territorio español por autonomías ha posibilitado el reparto de competencias entre el Estado y las Comunidades Autónomas. ${ }^{14}$ Corresponde a estas últimas las actuaciones en materia de protección de menores y la gestión y aplicación de los diferentes recursos de protección. Nos referimos a las medidas de apoyo a la familia, al internamiento en centros de protección, al acogimiento familiar y a la adopción nacional e internacional. Los cambios que ha sufrido la adopción internacional en España pueden examinarse en la Ley $21 / 1987$, de 11 de noviembre, por la que se modifican determinados artículos del Código Civil y de la Ley de enjuiciamiento civil en materia de adopción. ${ }^{15}$

Originariamente, antes de esta ley, los procedimientos de adopción se limitaban a un acto privado concertado entre los padres biológicos y los adoptivos. De modo que el control público de las adopciones ocurría únicamente

13. También son sugeridos por M.J. Montan y M.E. García (1991) «La adopción internacional en España», Infancia y sociedad 12: 19. Por su parte, Merín Cañada (1994: 83) indica los siguientes: primacía del interés del menor; carácter protector de la institución; democratización de la institución; garantía de legalidad de las actuaciones; agilización de trámites; intervención de autoridades públicas; y control público de la institución.

14. «La Constitución ampara y respeta los derechos históricos de los territorios forales. La actualización general de dicho régimen foral se llevará a cabo, en su caso, en el marco de la Constitución y de los Estatutos de Autonomía» (Disposición Adicional 1a).

15. BOE núm. 275 , de 17 de noviembre. 
cuando se tramitaba la inscripción del adoptado en el Registro Civil. Los intereses de los padres biológicos o guardadores, de los adoptivos y de los intermediarios eran los dominantes, quedando al margen las necesidades y derechos de los niños. En opinión de Hendricks (1995), este sistema ignoraba el interés del niño; imposibilitaba el control del proceso por las autoridades administrativas; permitía la acumulación de fortunas; suscitaba escándalos y prácticas abusivas; transfería una imagen desafortunada de la adopción; restaba posibilidades a la adopción de los niños y estigmatizaba a las familias que habían adoptado.

A partir de 1987, como decimos, ya son los Servicios Sociales de Menores de las Comunidades Autónomas los responsables de la guarda y/o tutela de los mismos, interviniendo en todo el proceso de adopción. Ahora, este recurso, como consta en el Preámbulo de la Ley 21/1987, se concibe como "[...] un instrumento de integración familiar, referido esencialmente a quienes más lo necesitan, y el beneficio del adoptado que se sobrepone, con el necesario equilibrio, a cualquier otro interés legítimo subyacente en el proceso de constitución».

En lo que concierne a la adopción internacional, se produce una modificación de los apartados 4 y 5 del artículo 9 del Código Civil, sobre derecho internacional privado. Se indica que el carácter y contenido de la filiación adoptiva se regirá por la Ley personal del hijo (apartado 4), y que la adopción constituida por juez español se hará según lo estipulado en la Ley española, a no ser que el adoptando tuviera su residencia habitual fuera de España, o residiendo en España, no hubiera adquirido en virtud de la adopción la nacionalidad española. En estos casos, así como en lo relacionado con la capacidad y consentimientos necesarios, regirá la Ley nacional del adoptando. De igual modo, la adopción constituida por la competente autoridad extranjera se regirá por la Ley del adoptando (apartado 5). Sin embargo, no se concreta en esta Ley la exigencia de un certificado en el que conste la idoneidad de los adoptantes ni respecto al compromiso de seguimiento de los menores, quedando estos extremos a merced de lo estipulado en la legislación de los países de origen de los niños. Será en la citada Ley 1/1996 donde se recoja, junto a los efectos de la adopción, este requisito de idoneidad de obligado cumplimiento. Así se contempla en la introducción de la Disposición Final Segunda, que modifica el párrafo quinto del artículo 9.5 del Código Civil: «No será reconocida en España como adopción la constituida en el extranjero por adoptante español, si los efectos de aquélla no se corresponden con los previstos en la legislación española. Tampoco lo será, mientras la entidad pública competente no haya declarado la idoneidad del adoptante, si este fuera español y estuviera domiciliado en España al tiempo de la adopción».

No obstante, ocurren situaciones de hecho muy complejas que han de resolver, posteriormente, las autoridades españolas responsables de la protección a través de procedimientos específicos. Las problemáticas más frecuentes están relacionadas con un inadecuado cumplimiento de los trámites exigidos por el Convenio de la Haya, con procedimientos que alberguen una adopción no 
plena o que, aun siéndolo, no se haya presentado el necesario certificado de idoneidad. En estos supuestos, el niño no podría ser inscrito en el Registro Civil y obtener la documentación española. Para resolver estas situaciones de falta de correspondencia entre las legislaciones de ambos países, el Ministerio de Justicia, a través de la Dirección General de los Registros y del Notariado, ha arbitrado unos procedimientos que posibilitan, a posteriori, la transformación de la adopción simple en plena (conforme al art. 27 del Convenio de la Haya) y la obtención del certificado de idoneidad.

Cuando en el país de origen se haya formalizado una adopción que no se corresponda con la adopción plena, que es la única reconocida en la legislación española, se puede emitir un visado por el Consulado español, tras la Resolución Judicial, que permitirá la entrada del niño/a en nuestro país. Posteriormente, los interesados podrán instar ante las autoridades judiciales españolas para perfeccionar el procedimiento y, de este modo, se procederá a dictar la correspondiente resolución judicial que habilite la inscripción del niño/a en el Registro Civil central ${ }^{16}$ (Madrid) y en el libro de familia.

También surgen problemas cuando la normativa del país de origen del niño reconoce a los padres adoptivos la facultad de extinguir la adopción por propia voluntad. Si esta circunstancia es la única diferencia con la adopción española, para evitar el trámite de constituir nuevamente la adopción en España por vía judicial, se pueden administrar soluciones que doten de eficacia jurídica a estas adopciones. Así se estipula en la Ley 18/1999, de 18 de mayo, de modificación del artículo 9, apartado 5, del Código Civil: ${ }^{17}$ "La atribución por la ley extranjera de un derecho de revocación de la adopción no impedirá el reconocimiento de ésta si se renuncia a tal derecho en documento público o por comparencia ante el encargado del Registro Civil» (Artículo Único).

Con independencia de las particularidades que revisten estos procesos adoptivos, lo cierto es que las formalizaciones no han cesado de crecer en la última década en España: 206 en el año 1992, 384 en 1993, 588 en 1994 y 645 en los diez primeros meses de 1995 (Ministerio de Trabajo y Asuntos Sociales 1995). Este crecimiento sigue siendo perceptible durante el período 19972001, ya claramente bajo la regulación de la Ley 1/1996 (cuadro 1). En efecto, el número de adopciones formalizadas en el año 2002 (3.625) con relación al año 1997 (942) supone un incremento próximo al $285 \%$. Por continentes, América Latina sigue aportando en los tres primeros años de este período el mayor contingente de niños, aunque será relegada al segundo lugar en el año

16. Igualmente, por Instrucción de 15 de febrero de 1999, la Dirección General de los Registros y del Notariado ha establecido, a efectos de preservar la intimidad familiar y a solicitud del matrimonio adoptante, la posibilidad de anotar en el Registro Civil «[...] una nueva inscripción en la que constarán solamente, además de los datos del nacimiento y del nacido, las circunstancias personales de los padres adoptivos y la oportuna referencia al matrimonio de éstos» (Regla Primera) (BOE n. ${ }^{\circ} 52$, de 2 de marzo). Esta instrucción posibilita el establecimiento de la plena igualdad con los hijos biológicos.

17. BOE núm. 119, de 19 de mayo. 
Cuadro 1. Adopciones por continentes y países de origen de los niños. Período 1997-2002 (números absolutos y porcentajes en cada casilla).

\begin{tabular}{lrrrrrrrrrrrr}
\hline Continente & 1997 & \multicolumn{1}{c}{$\%$} & \multicolumn{1}{c}{1998} & \multicolumn{1}{c}{$\%$} & $\mathbf{1 9 9 9}$ & $\%$ & 2000 & $\%$ & 2001 & $\%$ & 2002 & $\%$ \\
\hline América Latina & 631 & 66,99 & 960 & 64,55 & 895 & 44,61 & 905 & 29,56 & 721 & 21,03 & 593 & 16,35 \\
Asia & 214 & 22,71 & 295 & 19,84 & 443 & 22,08 & 686 & 22,40 & 1107 & 32,29 & 1586 & 43,75 \\
Europa del Este & 97 & 10,30 & 216 & 14,53 & 645 & 32,16 & 1.439 & 46,99 & 1569 & 45,77 & 1395 & 38,48 \\
África & 0 & 00,00 & 16 & 1,08 & 23 & 1,14 & 32 & 1,04 & 31 & 0,90 & 51 & 1,40 \\
\hline Total & 942 & 100 & 1.487 & 100 & 2.006 & 100 & 3.062 & 100 & 3.428 & 100 & 3.625 & 100 \\
\hline
\end{tabular}

Fuente: Consulados españoles en el extranjero. Tomado de la Dirección General de Acción Social, del Menor y de la Familia 2002: 74-77 (Ministerio de Trabajo y Asuntos Sociales). Elaboración propia.

Cuadro 2. Número de adopciones y tasas por cada 100.000 habitantes en España. Período 1991-2001 (números absolutos y tasas en cada casilla).

\begin{tabular}{lccccccccccc}
\hline Año & 1991 & 1992 & 1993 & 1994 & 1995 & 1996 & 1997 & 1998 & 1999 & 2000 & 2001 \\
\hline Adopciones & 907 & 947 & 936 & 884 & 885 & 1.025 & 883 & 875 & 868 & 964 & 1.075 \\
Tasas & 9,7 & 10,4 & 10,6 & 12,1 & 12,6 & 12,6 & 11,2 & 11,3 & 11,5 & 13,1 & 14,7 \\
\hline
\end{tabular}

Fuente: Comunidades Autónomas. Tomado de la Dirección General de Programas de Servicios Sociales 2001: 16 y 2002: 26 (Ministerio de Trabajo y Asuntos Sociales). Elaboración propia.

2000 y al tercero en el 2001, como consecuencia de la masiva entrada en España de niños originarios de países del Este de Europa y de Asia, que rompen esta tendencia. Por número de adopciones, en este orden, China (1.427), Federación de Rusia (809), Ucrania (358) y Colombia (271) han sido los países más solicitados.

Por el contrario, el número de adopciones nacionales ha observado un crecimiento sostenido entre los años 1991-2001, que tan sólo ha llegado al 18\%; y la tasa de adopciones — por cada 100.000 menores de 17 años - se ha incrementado en 5 puntos (cuadro 2). Las CC.AA. que han experimentado un mayor crecimiento han sido La Rioja, Andalucía y Murcia. La tasa de La Rioja ha pasado de ser en 1991 de 12,1 adopciones por 100.000 habitantes a 39,1 en 2001; la de Andalucía, de 6,5 en 1991 a 26,2 en 2001; y la de Murcia, de 5,1 se eleva a 21,9. Las CC.AA. que han sufrido un mayor descenso en las tasas de adopción han sido Ceuta-Melilla (-25,2 adopciones en 2001 respecto a 1991) y Aragón (-10,2 adopciones en 2001 respecto a 1991).

\section{Conclusiones}

La adopción internacional es una buena solución cuando no hay nadie que pueda hacerse cargo de un niño en su país de origen. El hecho de que esta adopción sea más compleja que la nacional no ha impedido que las adopciones de niños extranjeros se hayan disparado. De cara al futuro, si considera- 
mos una serie de factores de índole sociocultural y económica que anidan en la sociedad española, las cifras seguirán esta tendencia. No obstante, como está ocurriendo en otros países de nuestro entorno, es probable que las cifras tiendan a estabilizarse. Para evitar el tráfico de menores con motivo de una adopción internacional, las legislaciones de los distintos países deben acomodarse rigurosamente a lo estipulado en la Convención de los Derechos del Niño y en el Convenio de La Haya.

Las reflexiones vertidas en este trabajo también muestran cómo el cambio social está afectando a la concepción de la familia, de la infancia y del mismo proceso adoptivo. Por estas y otras razones, el futuro de la adopción en España está abierto a las modificaciones producidas en otras sociedades en torno a la adopción de personas mayores, al matrimonio y adopción homosexual, a la «adopción abierta» — que permite el contacto entre las familias biológicas $\mathrm{y}$ adoptivas-, a la filiación producida con motivo de la intervención de una "madre de alquiler», etc.

\section{Bibliografía}

Amorós, P. (1987). La adopción y el acogimiento familiar. Una perspectiva socieducativa. Madrid: Narcea.

Audusseau-Pouchard, M. (1997). Adoptar un hijo hoy. Barcelona: Planeta.

BORRÀs, A. (1996). «La regulación de la adopción en España: examen particular de la adopción internacional». Anuario de Psicología 71: 7-21.

Calvo Blanco, E. (1994). «Principios de la adopción internacional». Trabajo Social Hoy 3: 85-91.

CERnuda, P.; SÁEnZ-Díez, M. (1999). Los hijos más deseados. Madrid: El País-Aguilar.

Convención de las Naciones Unidas sobre los Derechos del Niño, de 20 de noviembre de 1989 (ratificación en BOE de 31 de diciembre).

Convenio de La Haya número XXVIII, de 25 de octubre de 1980, sobre los aspectos civiles de la sustracción internacional de menores (ratificado por España el 28 de mayo de 1987).

Convenio de La Haya número XXXIII, relativo a la protección del niño y a la cooperación en materia de adopción internacional, de 29 de mayo de 1993 (ratificación en BOE de 1 de agosto de 1995).

Convenio Europeo, hecho en Luxemburgo el 20 de mayo de 1980, relativo al reconocimiento y ejecución de decisiones en materia de custodia de menores, así como al restablecimiento de dicha custodia (ratificado por España el 9 de mayo de 1984).

Corva, P.; OrTega, E. (1997). «QQué necesitas para una adopción?». Mujer Hoy 5: 33-35.

Declaración sobre los principios sociales y jurídicos relativos a la protección y el bienestar de los niños, con particular referencia a la adopción y la colocación en hogares de guarda, en los planos nacional e internacional, de 3 de diciembre de 1986.

Decreto 454/19996, de 1 de octubre, sobre la habilitación de instituciones colaboradoras de integración familiar y acreditación de entidades colaboradoras de adopción internacional (BOJA n. ${ }^{\circ} 120$, de 19 de octubre).

Defensor del Pueblo Andaluz (1999). El Sistema de Protección de Menores. Tres tomos. Sevilla: Oficina del Defensor del Pueblo. 
DEFENSOR DEL PUEBLO ESPAÑOL (1991). Estudio sobre la situación del menor en centros asistenciales de internamiento y recomendaciones sobre el ejercicio de las funciones protectora y reformadora. Madrid: Oficina del Defensor del Pueblo.

Dell'Antonio, A.M. (1996). "Bambini e famiglie nell'adozione internazionale: il supporto delle istituzioni». Minori, Diritti e Giustizia 1 (suplemento): 3-74.

Dirección General de la FAMILIA y AdopCiOnes (1999). Guía para la adopción. Generalidad de Valencia: Consejería de Bienestar Social.

Direccion General de Programas de Servicios Sociales (2001). Estadística básica de protección a la infancia. Madrid: Ministerio de Asuntos Sociales, Dirección General de Acción Social, del Menor y de la Familia.

- (2002). Estadistica básica de protección a la infancia. Madrid: Ministerio de Trabajo y Asuntos Sociales, Dirección General de Acción Social, del Menor y de la Familia.

FÉDERATION ENFANCE ET FAMILLES D’ADOPTION (1998). «Nouvelles internationales». Congrés Adoption et Discriminations. Accueil 2-3: 47.

Galli, J.D.; VolPE, B. (1991). «Estudio psicológico de los candidatos a una adopción internacional: una propuesta de protocolo". Infancia y sociedad 12: 50-68.

GARCIA SANZ, F. (1997). "La intervención psicológica en las propuestas de adopción internacional. Una reflexión desde la práctica». Apuntes de Psicología 49-50: 201-218.

Giberti, E. (1992). «Adopción Internacional». En Giberti, E.; Chavanneau de GORE, S. Adopción y silencio. Buenos Aires: Sudamericana.

HENDRICKS, Z. (1995). «El papel de las agencias de adopción en su ámbito propio». Infancia y sociedad 33: 214-218.

Hoksbergen, R.A. (1997). "Turmoil for Adoptees during their Adolescence?». International Journal of Behavioral Development 20: 33-46.

Instrucción de 15 de febrero de 1999, de la Dirección General de los Registros y del Notariado, sobre constancia registral de la adopción (BOE n.o 52 , de 2 de marzo).

Ley 21/1987, de 11 de noviembre, por la que se modifican determinados artículos del Código Civil y de la Ley de enjuiciamiento civil en materia de adopción (BOE n.o 275 , de 17 de noviembre).

Ley Foral 67/2000, de 3 de julio, para la igualdad jurídica de las parejas estables (BON n. ${ }^{\circ} 82$, de 7 de julio).

Ley Orgánica 1/1996, de 15 de enero, de Protección Jurídica del Menor, de modificación parcial del Código Civil y de la Ley de Enjuiciamiento Civil (BOE n. ${ }^{\circ}$ 15, de 17 de enero).

Ley 18/1999, de 18 de mayo, de modificación del artículo 9, apartado 5, del Código Civil (BOE n.o 119, de 19 de mayo).

MARCH CERDÁ, M.X. (1993). La adopción en Mallorca. Una investigación evaluativa. Palma de Mallorca: Consejería de Gobernación.

Mato, J. (1997). «En proceso de cambio». Infancia y adopción 1: 5.

Merín CAÑAda, T. (1994). "La adopción internacional, hoy». Trabajo Social Hoy 3: 7783.

Ministerio de TRABAjO y ASUNTOS SOCIALES (1993). Información sobre la tramitación de adopciones internacionales (I). Madrid: Dirección General de Protección Jurídica del Menor.

- (1995). Información sobre la tramitación de adopciones internacionales (III). Madrid: Dirección General de Protección Jurídica del Menor.

Montané, M.J. (1996). "La evolución de la adopción internacional en España». Anuario de Psicología 71: 23-35. 
Montané, M.J.; García, M.E. (1991). «La adopción internacional en España». Infancia y sociedad 12: 18-23.

OCON DOMingO, J. (2000). «Pasado y presente de las instituciones de acogida para menores en España: un análisis particular de la Comunidad Autónoma de Andalucía». Revista del Ministerio de Trabajo y Asuntos Sociales 25: 79-91.

- (2003). Aspectos psicosociales de la adopción en Andalucía (una aproximación sociohistórica y jurídico-administrativa). Universidad de Granada: Departamento de Sociología, Facultad de Ciencias Políticas y Sociología.

PALACIOS et al. (1997). La adopción en Andalucía. Sevilla: Junta de Andalucía, Consejería de Asuntos Sociales.

Zugravescu, A.; IACOVescu, A. (1991). «La adopción internacional en Rumania». Infancia y sociedad 12: 112-121. 